\title{
Modelling the influence of meteoric smoke particles on artificial heating in the D-region
}

\author{
Margaretha Myrvang ${ }^{1}$, Carsten Baumann ${ }^{2}$, and Ingrid Mann ${ }^{1}$ \\ ${ }^{1}$ UiT The Arctic University of Norway, Department of Physics and Technology, \\ Postboks 6050 Langnes, 9037 Troms $\varnothing$, Norway \\ ${ }^{2}$ German Aerospace Center, Institute for Solar-Terrestrial Physics, 17235 Neustrelitz, Germany
}

Correspondence: Margaretha Myrvang (margaretha.myrvang@uit.no)

Received: 11 July 2021 - Discussion started: 20 July 2021

Revised: 27 October 2021 - Accepted: 11 November 2021 - Published: 17 December 2021

\begin{abstract}
We investigate if the presence of meteoric smoke particles (MSPs) influences the electron temperature during artificial heating in the D-region. By transferring the energy of powerful high-frequency radio waves into thermal energy of electrons, artificial heating increases the electron temperature. Artificial heating depends on the height variation of electron density. The presence of MSPs can influence the electron density through charging of MSPs by electrons, which can reduce the number of free electrons and even result in height regions with strongly reduced electron density, so-called electron bite-outs. We simulate the influence of the artificial heating by calculating the intensity of the upwardpropagating radio wave. The electron temperature at each height is derived from the balance of radio wave absorption and cooling through elastic and inelastic collisions with neutral species.

The influence of MSPs is investigated by including results from a one-dimensional height-dependent ionospheric model that includes electrons, positively and negatively charged ions, neutral MSPs, singly positively and singly negatively charged MSPs, and photochemistry such as photoionization and photodetachment. We apply typical ionospheric conditions and find that MSPs can influence both the magnitude and the height profile of the heated electron temperature above $80 \mathrm{~km}$; however, this depends on ionospheric conditions. During night, the presence of MSPs leads to more efficient heating and thus a higher electron temperature above altitudes of $80 \mathrm{~km}$. We found differences of up to $1000 \mathrm{~K}$ in electron temperature for calculations with and without MSPs. When MSPs are present, the heated electron temperature decreases more slowly. The presence of MSPs does not
\end{abstract}

much affect the heating below $80 \mathrm{~km}$ for night conditions. For day conditions, the difference between the heated electron temperature with MSPs and without MSPs is less than $25 \mathrm{~K}$.

We also investigate model runs using MSP number density profiles for autumn, summer and winter. The night-time electron temperature is expected to be $280 \mathrm{~K}$ hotter in autumn than during winter conditions, while the sunlit D-region is $8 \mathrm{~K}$ cooler for autumn MSP conditions than for the summer case, depending on altitude. Finally, an investigation of the electron attachment efficiency to MSPs shows a significant impact on the amount of chargeable dust and consequently on the electron temperature.

\section{Introduction}

Meteoric smoke particles (MSPs) are small nanometer-sized dust particles (Hunten et al., 1980; Plane, 2012). They can change the D-region charge balance by influencing the chemical processes through charging of MSPs by electrons and ions (see Baumann et al., 2015). By changing the charge balance, MSPs can influence artificial heating. The overall charge balance in the D-region is complex with positive ions, negative ions and cluster ions (Verronen et al., 2016).

The MSPs form as a result of meteor ablation that deposits the meteoric material in the higher atmosphere, which condenses to MSPs of sizes up to a few nanometers (Plane, 2004). Measurements on board rockets have detected both negatively and positively charged MSPs, indicating that MSPs can influence plasma densities in the D-region through 
charging of MSPs by electrons and ions (Friedrich et al., 2012). Charging of MSPs influences the charge balance mainly through electron attachment to MSPs, which can results in height regions with reduced electron density, socalled electron bite-outs. Electron bite-outs change the height profile of the electron density, and this reduction in electron density occurs in altitude regions where the MSPs are most abundant. Electron bite-outs within the height profile of the electron density can affect the electron temperature during artificial heating, as shown by Kassa et al. (2005).

A heater transmits powerful high-frequency radio waves into the ionosphere during artificial heating experiments. In the collisional plasma of the ionospheric D-region, electrons absorb the radio wave energy transmitted from the heater and heat up, increasing the electron temperature. Consequently, the intensity of the radio wave decreases with height (Rietveld et al., 1986; Belova et al., 1995; Kero et al., 2000 , 2008). Artificial heating can also induce different phenomena in the ionosphere, like for instance ion upwelling (Kosch et al., 2010) and artificial optical emission (Kosch et al., 2000, 2014) in the F-region. In the D-region, researchers have found that artificial heating can influence polar mesospheric summer echoes (PMSEs) (Chilson et al., 2000; Havnes et al., 2004; Biebricher and Havnes, 2012). The PMSEs form in the presence of atmospheric turbulence and charged ice particles, and it is assumed that the presence of MSPs in the D-region facilitates the formation of ice particles.

The aim of our study is to numerically model the electron temperature during artificial heating and include the height variation of electron bite-outs by using an ionospheric model (Baumann et al., 2013) with MSPs. As a comparison, we also model without MSPs. The one-dimensional heightdependent ionospheric model is for quiet ionospheric conditions and includes MSPs and photochemistry such as photoionization and photodetachment. We calculate the artificial heating with different radio wave frequencies and higher or lower radio wave power to investigate if this influences the electron temperature and to check the robustness of our results. We will compare night and day conditions to see if a higher electron density during daytime influences the modelled electron temperature. In addition, we investigate the seasonal variation of the MSPs abundance, as well as the role of the electron attachment efficiency to MSPs for the heated electron temperature.

This paper is organized as follows. In Sect. 2 we present a detailed theoretical background and numerical modelling of artificial heating in the D-region. Section 3 gives a brief description of the ionospheric model. In Sect. 4 we introduce the results. Section 5 presents the discussion.

\section{Artificial heating in the D-region}

Powerful high-frequency radio waves can heat up electrons in the ionospheric D-region by artificial heating experiments. The higher temperature of the electrons can lead to various phenomena in the whole ionosphere (e.g. Robinson, 1989, and references therein). Artificial heating increases the electron temperature by transferring the radio wave energy into thermal energy of electrons (Rietveld et al., 1986; Kero et al., 2007, 2008). Modelling of artificial heating in D-region altitudes shows an increase in electron temperature by a factor of 10 (Belova et al., 1995; Kero et al., 2000). The EISCAT (European Incoherent Scatter Scientific Association) high-power high-frequency heating facility located in Troms $\varnothing$, Norway, transmits powerful high-frequency radio waves into the ionosphere during artificial heating experiments. The EISCAT radar, also located in Troms $\varnothing$, Norway, can observe the ionosphere during these heating experiments. The EISCAT heating facility in Troms $\varnothing$ has three different antenna arrays consisting of crossed full-wave dipoles with a frequency range of 3.85-8 MHz. There are 12 transmitters that can adjust the power output from 200 to $1200 \mathrm{MW}$, depending on the used radio frequency. The dipoles can transmit ordinary $(O)$ circular polarization mode or extraordinary $(X)$ circular polarization mode (Rietveld et al., 2016). The following model of the heated ionosphere, described in the next section, uses these experimental parameters of the EISCAT heating facility (Rietveld et al., 1993).

\subsection{Description of model}

This section describes the physical background of the artificial electron heating. For the implementation of the artificial electron heating, we rely on earlier work done by Rietveld et al. (1986), Belova et al. (1995), Kero et al. (2000, 2007) and Kassa et al. (2005). Note that the model described in this section only covers the lower ionosphere. The heater transmits a powerful high-frequency radio wave that propagates through the cold, magnetized, collisional plasma of the ionospheric D-region. The intensity $I$ or energy of the radio wave varies with height $h$ according to

$\frac{\mathrm{d} I}{\mathrm{~d} h}=-2 k I$,

where $k$ is the absorption coefficient, given as

$k=-\frac{\omega \operatorname{Im}(n)}{c}$.

In Eq. (2), $\omega$ is the angular frequency of the heating radio wave, $\operatorname{Im}(n)$ is the imaginary part of the refractive index $n$ and $c$ is the speed of light. When integrated, Eq. (1) in combination with Eq. (2) yields the following expression for the intensity:

$I(h)=\frac{\mathrm{ERP}}{4 \pi h^{2}} \exp \left(\frac{2 \omega}{c} \int_{0}^{h} \operatorname{Im}(n) \mathrm{d} h\right)$, 
where ERP is the effective radiated power. For solving Eq. (3), we need an expression for the refractive index $n$. We can derive the refractive index by using the AppletonHartree dispersion relation, which describes the radio wave propagation in a cold magnetized plasma and which can be applied to the ionospheric D-region. It describes the refractive index as

$$
n^{2}=1-\frac{X}{1-i Z-\frac{(Y \sin \theta)^{2}}{2(1-X-i Z)} \pm \sqrt{\frac{\left(Y \sin \theta \theta^{4}\right.}{4(1-X-i Z)^{2}}+(Y \cos \theta)^{2}}},
$$

where $\theta$ is the angle between the wave vector and the direction of the magnetic field. Here, $(+)$ and $(-)$ represent the ordinary and extraordinary polarization modes, respectively. Note that the refractive index is complex: $n=n_{1}+i n_{2}$. If the imaginary part is less than zero, the wave is damped. The wave damping is caused by wave energy loss through absorption by the plasma while the wave propagates through the ionosphere. Due to its lower mass, electrons absorb the energy and are thus heated, while ions and neutrals remain unheated in comparison. The dimensionless $X, Y$ and $Z$ are normalized frequencies, defined as

$X=\frac{\omega_{\mathrm{pe}}^{2}}{\omega^{2}}=\frac{N_{\mathrm{e}} e^{2}}{\varepsilon_{0} m_{\mathrm{e}} \omega^{2}}$,

$Y=\frac{\omega_{\mathrm{ge}}}{\omega}=\frac{e B}{m_{\mathrm{e}}} \omega$

$Z=\frac{\nu_{\text {en }}}{\omega}$,

where $N_{\mathrm{e}}$ is electron density, $e$ is unit charge, $\varepsilon_{0}$ is the permittivity of vacuum, $m_{\mathrm{e}}$ is electron mass, $B$ is the Earth's magnetic field and $v_{\mathrm{en}}$ is the electron-neutral collision frequency. How the electron-neutral collision frequency from Eq. (7) depends on electron temperature is taken from Dalgarno et al. (1967):

$$
\begin{aligned}
v_{\text {en }} & =1.7 \times 10^{-11}\left[\mathrm{~N}_{2}\right] T_{\mathrm{e}}+3.8 \times 10^{-10}\left[\mathrm{O}_{2}\right] \sqrt{T_{\mathrm{e}}} \\
& +1.4 \times 10^{-10}[\mathrm{O}] \sqrt{T_{\mathrm{e}}},
\end{aligned}
$$

where $\left[\mathrm{N}_{2}\right]$ is the number density of molecular nitrogen, $\left[\mathrm{O}_{2}\right]$ is the number density of molecular oxygen, $[\mathrm{O}]$ is the number density of atomic oxygen and $T_{\mathrm{e}}$ is the electron temperature. Neutral densities are in units of cubic centimetre $\left(\mathrm{cm}^{-3}\right)$ and temperature in kelvin (K). Through $v_{\mathrm{en}}$, the refractive index depends on the electron temperature. The electron-neutral collision frequency is high in the D-region due to the relatively low electron density in comparison to the neutral density. Therefore, electron ohmic heating is the dominant D-region ionospheric response to heating. In ohmic heating, electrons oscillating parallel to the radio wave electric field collide with neutrals. This causes a phase shift between the direction of the radio wave electric field and the direction of electron oscillation. Overall, electrons are scattered in a random direction. This random motion of electrons leads to absorption of wave energy, where the wave energy is transferred into thermal energy of electrons, increasing the electron temperature. To find the increased electron temperature, we use the electron energy balance equation, which describes local electron energy conservation. Solving the electron energy equation gives us the electron temperature time variation due to energy input from the heater and cooling through collisions with neutrals. We have neglected thermal conductivity due to high neutral density in the D-region and neglected plasma transport. The electron energy equation is then given as

$$
\frac{\mathrm{d} T_{\mathrm{e}}}{\mathrm{d} t}=\frac{2}{3 k_{\mathrm{b}} N_{\mathrm{e}}}\left(Q\left(T_{\mathrm{e}}\right)-L\left(T_{\mathrm{e}}\right)\right),
$$

where $k_{\mathrm{b}}$ is Boltzmann's constant. Equation (9) is non-linear differential equation. Here $Q\left(T_{\mathrm{e}}\right)$ is the power absorbed by electrons per volume:

$Q\left(T_{\mathrm{e}}\right)=2 k\left(T_{\mathrm{e}}\right) I(h)=\frac{2 \omega}{c} \operatorname{Im}(n) I(h)$.

The electrons lose energy and are thus cooled through elastic and inelastic collisions with neutral species, where the inelastic collisions can excite vibrational and rotational states. The sum of all energy losses is given by the energy loss function $L\left(T_{\mathrm{e}}\right)$; this represents the electron cooling rates. Our cooling rates include vibrational and rotational excitation of molecular oxygen (Pavlov, 1998b) and of molecular nitrogen (Pavlov, 1998a), excitation of fine structure levels of atomic oxygen (Pavlov and Berringston, 1999), and elastic collisions between electrons and neutral species (Schunk and Nagy, 1978). Due to the low electron density in the D-region, we neglect electron-ion collision. More detailed descriptions of the electron cooling rates are given in Appendix B. When the heater is switched on, the electron temperature increases from its initial temperature, which is equal to the neutral temperature in the D-region, to a higher heated electron temperature. The heating time for this temperature increase is less than $1 \mathrm{~ms}$, due to the high collision frequency, $v_{\mathrm{en}}$, in the D-region. After less than $1 \mathrm{~ms}$ the electron temperature has reached thermal equilibrium where $\mathrm{d} T_{\mathrm{e}} / \mathrm{d} t=0$. In the cases where the heating modulation time is much longer than the heating time for the electron temperature, we can simplify Eq. (9) to

$Q\left(T_{\mathrm{e}}\right)-L\left(T_{\mathrm{e}}\right)=0$.

\subsubsection{Implementation of model}

To compute the electron temperatures during heating, we numerically solve Eq. (11). At the first height the intensity is $I_{0}=\mathrm{ERP} / 4 \pi h^{2}$, i.e. the undamped radio wave. We then compute $Q\left(T_{\mathrm{e}}\right)$ from Eq. (10) by using the intensity $I_{0}$, where $Q\left(T_{\mathrm{e}}\right)$ is a function of $T_{\mathrm{e}}$. We use the intensity $I_{0}$ to solve $Q\left(T_{\mathrm{e}}\right)-L\left(T_{\mathrm{e}}\right)=0$ for the electron temperature by using an algorithm that combines the inverse quadratic interpolation method, bisection method and secant method (Brent, 
1973; Forsythe et al., 1977). By solving $Q\left(T_{\mathrm{e}}\right)-L\left(T_{\mathrm{e}}\right)=0$, we find the zero-point of Eq. (11), which gives us a new electron temperature. This new, modified electron temperature changes the refractive index since the electron-neutral collision frequency depends on electron temperature. With the changed refractive index, we recalculate the intensity, taking into account the loss due to absorption. We compute the intensity numerically by approximating the integral in Eq. (3) as a sum:

$I(h)=\frac{\mathrm{ERP}}{4 \pi h^{2}} \exp \left(\frac{2 \omega}{c} \sum_{h^{\prime}=60 \mathrm{~km}}^{h^{\prime}=h} \operatorname{Im}\left(n\left(h^{\prime}\right)\right) \Delta h\right)$,

where the first part ERP $/ 4 \pi h^{2}$ represents the undamped radio wave, and the part in the exponential function represents the damping effect due to absorption. The distance between each height is $\Delta h=\left(h^{\prime}\right)-\left(h^{\prime}-1\right)$. For our case $\Delta h=1 \mathrm{~km}$, and $\Delta h$ is constant for all altitudes. In the next iteration, the intensity has changed, so there is a new zero-point for $Q\left(T_{\mathrm{e}}\right)-L\left(T_{\mathrm{e}}\right)=0$, which we compute. Figure 1 shows $Q-L$ as a function of $T_{\mathrm{e}}$. This figure illustrate that loss due to absorption can change the location of the zero-point of $Q-L$. We have used the following parameters to calculate $Q-L$ : height of $75 \mathrm{~km}$, ionospheric night conditions, model run with the presence of MSPs, frequency of $5 \mathrm{MHz}$ and power of $700 \mathrm{MW}$. Figure 1 shows the zero-point of $Q-L$ with $I_{0}$, illustrated as a blue star, and the zero-point of $Q-L$ with the changed intensity $I_{1}$, illustrated as a magenta star. We see in Fig. 1 that the zero-point of $Q-L$ is different for $I_{0}$ and $I_{1}$. This process with a new, modified electron temperature, which changes the intensity, is repeated in an iteration scheme. The neutral temperature is the starting point in the iteration scheme. The iteration scheme is repeated until the change in the electron temperature is very small, i.e. when $T_{\mathrm{e}}$ converges. This equation visualizes the iteration for the intensity:

$I(h+1)=I_{0}-\mathrm{d} I(h)-\mathrm{d} I(h+1)$,

where $I_{0}=$ ERP. Here $\mathrm{d} I(h)$ represents absorption at heights below, and $\mathrm{d} I(h+1)$ represents absorption at the current height. Before we move to the next height, we sum all the absorption so that for the next height we take into account all absorption below. In the next height, we repeat the procedure described for the first height and calculate the heated electron temperature and the new intensity. This is done for all heights, moving upward from the initial height to the final height. Our altitude range is $60-120 \mathrm{~km}$. The ionospheric D-region varies in altitude range from about 50 to $100 \mathrm{~km}$; however, we model up to $120 \mathrm{~km}$ to see if the electron temperature at altitudes above $100 \mathrm{~km}$ is influenced by the presence of MSPs at lower altitudes below.

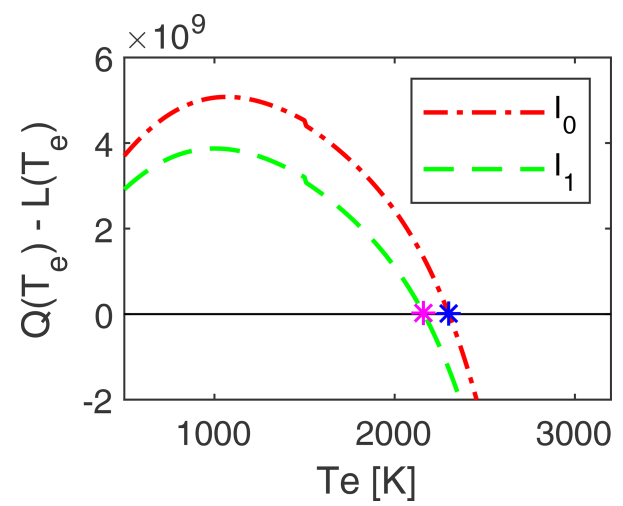

Figure 1. Illustration of $Q\left(T_{\mathrm{e}}\right)-L\left(T_{\mathrm{e}}\right)$ as a function of electron temperature with intensity $I_{0}$ (the undamped radio wave) and $I_{1}$ (radio wave with damping). Here $I_{0}>I_{1}$. The units of $Q\left(T_{\mathrm{e}}\right)-L\left(T_{\mathrm{e}}\right)$ are energy per volume per second, i.e. $\mathrm{eV} \mathrm{m}^{-3} \mathrm{~s}-1$. With a different intensity, we change the location of the zero-point, where $Q\left(T_{\mathrm{e}}\right)-L\left(T_{\mathrm{e}}\right)=0$. The zero-point is marked as a blue star for $I_{0}$ or a magenta star for $I_{1}$. We have used the following parameters to calculate $Q-L$ : height of $75 \mathrm{~km}$, ionospheric night conditions, model run with the presence of MSPs, frequency of $5 \mathrm{MHz}$ and power of $700 \mathrm{MW}$.

We model the height-dependent heated electron temperature with initial height profiles for the following parameters: Earth's magnetic field, electron density, neutral temperature, neutral densities of molecular nitrogen, molecular oxygen and atomic oxygen. For Earth's magnetic field, we use a dipole approximation (Brekke, 2013). The magnetic field goes into Eq. (6), which we use to compute the refractive index in Eq. (4). We compare day and night conditions to see if a higher ionization level, as during day conditions, has an influence on the heated electron temperature. The used electron density height profiles during day and night conditions come from an ionospheric model by Baumann et al. (2013). The neutral temperature and neutral densities are from the MSISE-90 model (Hedin, 1991; Picone et al., 2002) with the same date, time and location as used for the ionospheric model. The parameters for the EISCAT heating radio wave include polarization, radio wave frequency and effective radiated power (ERP). The model calculations are done with $\mathrm{X}$-mode transmission polarization. For the radio wave frequency and ERP, we assume a number of different typical values to see if this influences the heated electron temperature with MSPs and without MSPs. We ran the model for four different cases; see Table 1 (Erik Varberg, personal communication, 2021). Figure 2 shows a schematic on how we computed the heated electron temperature by combining artificial heating and the electron density from the ionospheric model. In the next section we briefly describe the ionospheric model. 


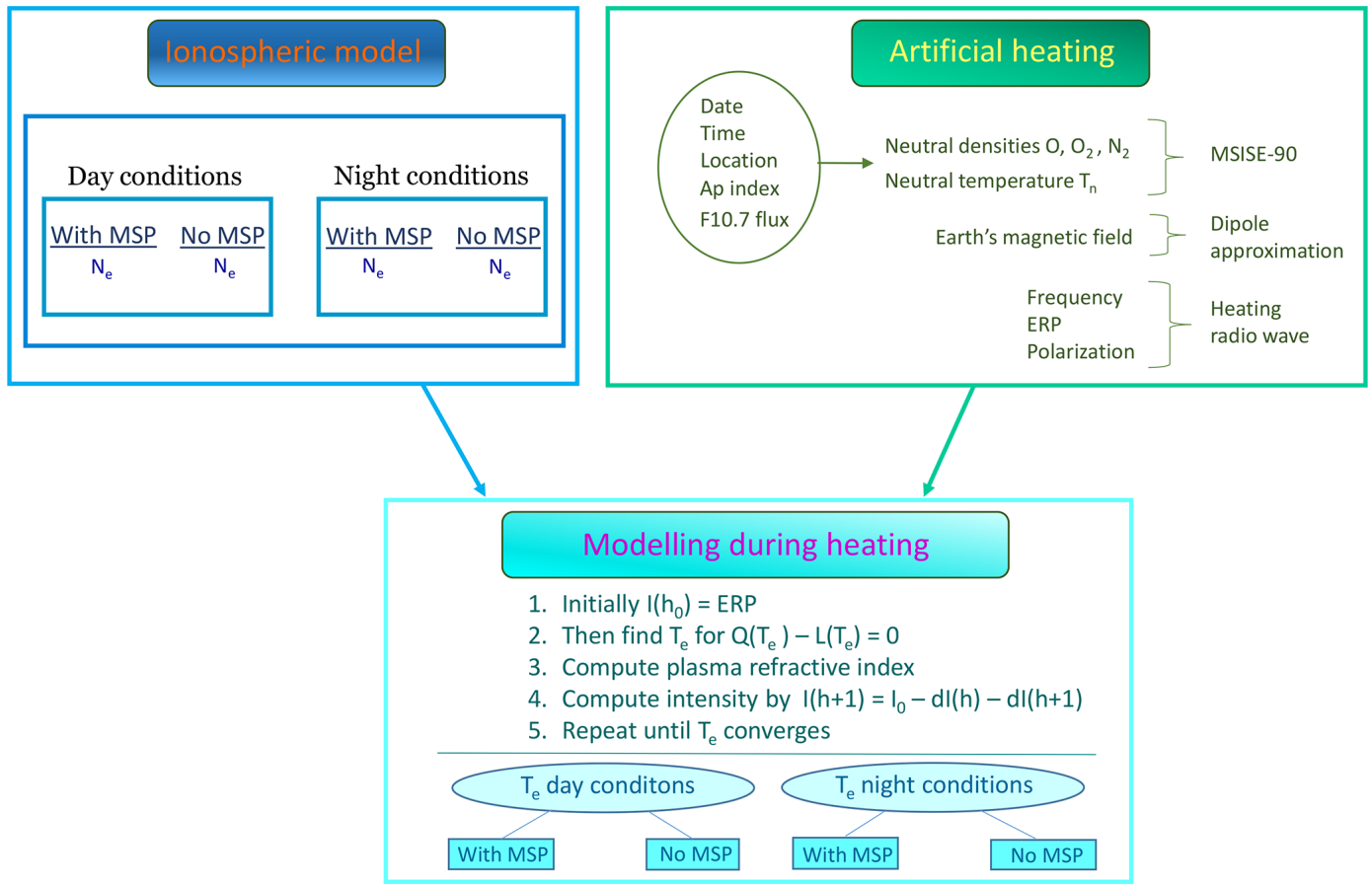

Figure 2. Schematic showing how we combined artificial heating and the electron density from the ionospheric model in order to compute the heated electron temperature. The parameters for artificial heating include frequency, effective radiated power (ERP) and polarization of the heating radio wave, Earth's magnetic field, and neutral densities and neutral temperature. We perform the modelling during heating at each height from below before going to the next height, moving upward from the initial height to the final height.

Table 1. The frequencies and effective radiated power (ERP) used in the study.

\begin{tabular}{llll}
\hline Case 1 & Case 2 & Case 3 & Case 4 \\
\hline $4 \mathrm{MHz}$ & $5.5 \mathrm{MHz}$ & $5.5 \mathrm{MHz}$ & $7.5 \mathrm{MHz}$ \\
$200 \mathrm{MW}$ & $300 \mathrm{MW}$ & $600 \mathrm{MW}$ & $1200 \mathrm{MW}$ \\
\hline
\end{tabular}

\section{Background ionospheric model}

Here we give a brief description of a one-dimensional heightdependent ionospheric model for the D-region, which includes MSPs, developed by Baumann et al. (2013). For the full description, see Baumann et al. (2013) and references therein. The one-dimensional height-dependent ionospheric model is run for quiet ionospheric conditions between heights of $60-120 \mathrm{~km}$ and includes electrons, positively and negatively charged ions, neutral MSPs, and singly positively and singly negatively charged MSP. Multiply charged dust is unlikely to occur since the MSPs are very small. Initial conditions for the height and size-dependent MSP number density profile come from Megner et al. (2006). The size range is from 0.2 to $41 \mathrm{~nm}$. Above $100 \mathrm{~km}$, the number density of MSPs is assumed to be very small. Megner et al. (2006) calculates the MSP number density profile by using a one-dimensional model, where the MSP height distri- bution varies with size. The number density of smaller MSPs (less than $15 \mathrm{~nm}$ ) increases with altitude, while larger sizes are more abundant at lower altitudes between $60-70 \mathrm{~km}$. Overall the number density of MSPs increases from $60 \mathrm{~km}$ to a maximum at around $80-83 \mathrm{~km}$, and then decreases above. For an overview of the different MSP number density profiles, we refer the reader to Fig. A1 in Appendix A. For the charging of a MSP by electrons, the electron attachment efficiency is the probability of a MSP capturing an electron. This probability is size-dependent. Megner and Gumbel (2009) assume a probability of zero for sizes less than $0.25 \mathrm{~nm}$, a probability of 1 for sizes larger than $1.5 \mathrm{~nm}$ and for sizes between 0.25 and $1.5 \mathrm{~nm}$ they assume a probability that increases linearly. Baumann et al. (2013) apply the electron attachment efficiency $\left(\gamma_{\text {charging }}\right)$ from Megner and Gumbel (2009) to the ionospheric model. Megner and Gumbel (2009) proposed this charging efficiency based on a laboratory study on the charging of water ice clusters. The size dependence of the charging efficiency is probably a function of dust composition. Therefore, we add two alternative scenarios of this efficiency to study its possible impact on the electron heating. Table 2 summarizes the different electron attachment efficiencies applied in our study. The computation scheme includes chemical reactions like the standard plasma reactions for electrons and ions, plasma capture reactions by MSPs and photoreactions such as photoionization and photodetachment of MSPs. The standard plasma reactions include ionization, 
dissociative recombination, electron attachment to neutrals, electron detachment from negative ions and ion-ion recombination. Figure 3 shows a schematic of the underlying ionospheric model. By solving the time-dependent rate equations for the six species, the ionospheric model computes number densities of electrons, ions and MSPs. The rate equations describes how the concentration of a given species varies with time by looking at the local production rate and local loss rate. The modelling is done with and without the MSPs, as a comparison. For the initial conditions, the following parameters are taken from the Sodankylä Ion Chemistry (SIC) model (Turunen et al., 1996): number densities of electrons, positive ions and negative ions, the temperature of ions and electrons, the reaction rate coefficients for the standard plasma reactions, and average ion mass. The SIC model was run for conditions on 8 September 2010 at Andenes, Norway; $69^{\circ} \mathrm{N}, 16^{\circ} \mathrm{E}$; at 23:55 LT (night conditions) and 12:15 LT (day conditions). We ran the ionospheric model with different MSP number density profiles: autumn conditions (8 September), winter conditions (1 January) and summer conditions (20 July). The model runs with different MSP number densities are performed with the following autumn ionospheric conditions: autumn MSP distribution for night and day conditions, winter MSP distribution for night conditions, and summer MSP distribution for day conditions. The MSP winter and summer distributions come from Megner et al. (2008).

\section{Results}

\subsection{Night conditions}

This section presents results for the electron temperature modelled during artificial heating with and without the presence of MSPs for night conditions. The main results are that from $80 \mathrm{~km}$ and above the heated electron temperature is higher when MSPs are present, and this applies to all cases with different frequencies and ERP. In Fig. 4 we show results for electron density influenced by MSPs. As a comparison, we ran the model without the influence of MSPs. We see in Fig. 4 that there is a reduction in electron density, an electron bite-out, due to the presence of MSPs, predominantly between heights $80-100 \mathrm{~km}$. There is an electron bite-out between $70-80 \mathrm{~km}$, but it is significantly smaller than between $80-100 \mathrm{~km}$. Between $100-120 \mathrm{~km}$, the electron bite-outs are not present. We see that electron bite-outs change the height profile of the electron density.

Figure 5 presents results for the heated electron temperature for cases 1-4. The heated electron temperature is computed with the electron density from Fig. 4. In Fig. 5 we see that the electron temperature is higher for altitudes above $80 \mathrm{~km}$ when MSPs are present. The shape of the height profile varies as well, where the heated electron temperature decreases more slowly when MSPs are present so that the
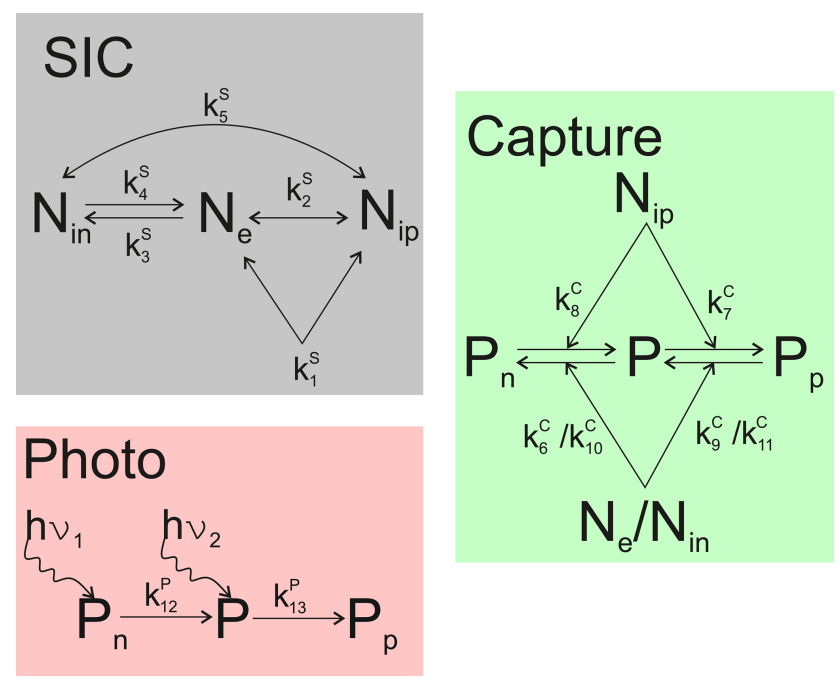

Figure 3. Schematic of the underlying ionospheric model. Greyshaded reactions are SIC reaction rates generalized to the reduced set of ionospheric constituents ( $N_{\mathrm{in}}$ - negative ions, $N_{\mathrm{e}}$ - electrons, $N_{\text {ip }}$ - positive ions), green-shaded reactions are charge-carrier capture processes by MSP $\left(P_{\mathrm{n}}-\right.$ negative MSP, $P$ - neutral MSP, $P_{\mathrm{p}}$ - positive MSP), and red-shaded reactions are the photodetachment and photoionization of MSP, where the wiggly arrow indicates the incoming solar photon that detaches an electron from the surface of a neutral or negatively charged MSP. The $k_{1}-k_{13}$ are reaction rate coefficients. For details on the individual reactions, see Baumann et al. (2013).

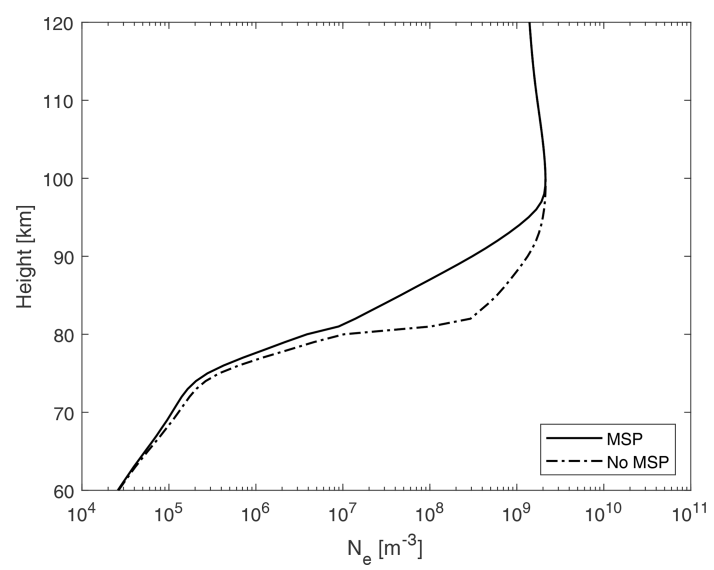

Figure 4. Electron density during night conditions, where the electron density comes from the ionospheric model. The legend shows model run with and without the MSPs.

shape of the height profile is more flat. Without MSPs, the electron temperature decreases faster and it has a different overall shape. Below $80 \mathrm{~km}$, the heated electron temperature is the same with and without MSPs. A comparison of the four different cases shows similar results for the heated electron temperature in Fig. 5. The electron temperature is higher when MSPs are present for all five different cases and the shape is also similar. We also see that a higher ERP results 
Table 2. The different electron attachment efficiencies ( $\gamma_{\text {charging }}$ ), where $r$ is the MSP radius. "MSP, I": the probability is 1 for all MSP sizes. "MSP, II": the probability is zero for MSP sizes below $0.25 \mathrm{~nm}$; between 0.25 to $1.5 \mathrm{~nm}$ the probability increases linearly, and for sizes larger than $1.5 \mathrm{~nm}$ the probability is 1. "MSP, III": the probability is zero for MSP sizes below $1.5 \mathrm{~nm}$ and 1 for sizes larger than $1.5 \mathrm{~nm}$. Note that "MSP, II" comes from Megner and Gumbel (2009).

\begin{tabular}{|c|c|c|c|c|c|}
\hline MSP, I & & MSP & & & MSP, III \\
\hline$\gamma_{\text {charging }}=\{1, \quad$ for all $r$ & $\gamma_{\text {charging }}=$ & $\begin{array}{l}0, \\
0.8 \cdot r-0.2, \\
1,\end{array}$ & $\begin{array}{l}\text { for } r<0.25 \mathrm{~nm} \\
\text { for } 0.25 \leq r \leq 1.5 \mathrm{~nm} \\
\text { for } r>1.5 \mathrm{~nm}\end{array}$ & $\gamma_{\text {charging }}=$ & $\begin{array}{l}0, \quad \text { for } r \leq 1.5 \mathrm{~nm} \\
1, \quad \text { for } r>1.5 \mathrm{~nm}\end{array}$ \\
\hline
\end{tabular}

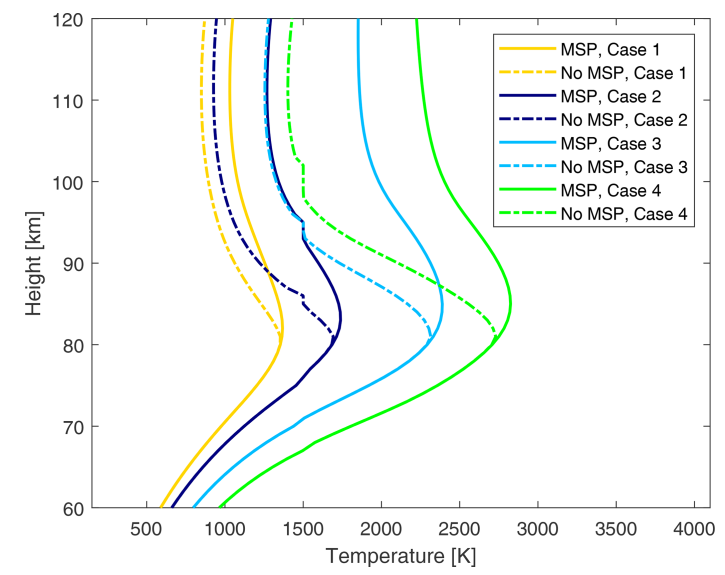

Figure 5. Results for night conditions for modelled electron temperature during heating as a function of height for cases 1-4. The legend shows model run with and without the MSPs and for the different cases $1-4$.

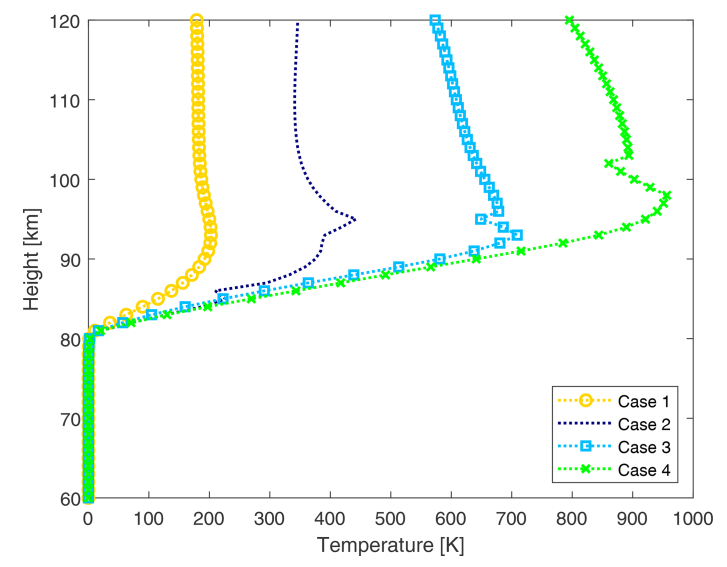

Figure 6. Absolute difference between the electron temperature modelled with and without the MSPs during night conditions. The legend shows model run for the different cases $1-4$.

in a higher electron temperature, where $T_{\mathrm{e}}$ reaches almost $3000 \mathrm{~K}$ for case 4 with ERP of $1200 \mathrm{MW}$.

Figure 6 shows the absolute difference between the heated electron temperature modelled with and without MSPs, i.e. how much higher the heated electron temperature is with MSPs compared to without MSPs. The difference in $T_{\mathrm{e}}$ in-
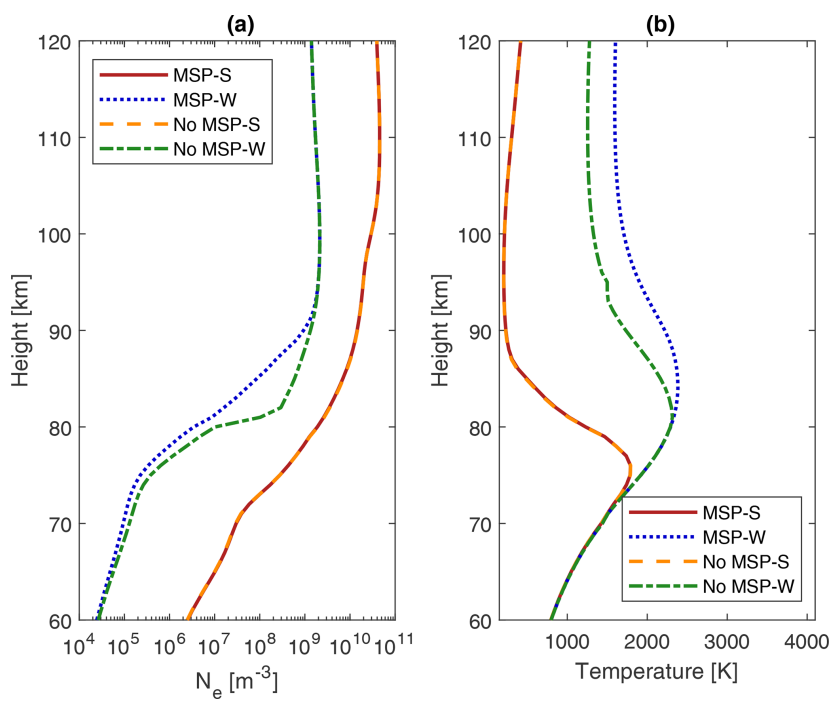

Figure 7. Results for MSP winter distribution (night ionospheric conditions) and MSP summer distribution (day ionospheric conditions). The frequency is $5.5 \mathrm{MHz}$ and the ERP is $600 \mathrm{MW}$. Panel (a) shows electron density, and panel (b) shows heated electron temperature. We also show the model run without MSPs. In the legend, "S" stands for summer conditions, while "W" stands for winter conditions.

creases from $80 \mathrm{~km}$ and reaches a maximum between 90 $100 \mathrm{~km}$. From $100 \mathrm{~km}$ and on, the difference in $T_{\mathrm{e}}$ starts to decrease. The difference in $T_{\mathrm{e}}$ increases for higher ERP. For case 4 with a frequency of $7.5 \mathrm{MHz}$ and ERP of $1200 \mathrm{MW}$, the difference in $T_{\mathrm{e}}$ at around $100 \mathrm{~km}$ is almost $1000 \mathrm{~K}$, while for case 3 with a frequency of $5.5 \mathrm{MHz}$ and ERP of $600 \mathrm{MW}$ the difference in $T_{\mathrm{e}}$ at around $95 \mathrm{~km}$ is $\sim 700 \mathrm{~K}$. For the lower ERP of $200 \mathrm{MW}$ with frequency $4 \mathrm{MHz}$ (case 1) or ERP of $300 \mathrm{MW}$ with frequencies $5.5 \mathrm{MHz}$ (case 2), the difference in $T_{\mathrm{e}}$ is between $200-500 \mathrm{~K}$ at $95 \mathrm{~km}$.

In Fig. 5 a small feature appears in some of the plots when the electron temperature is around $1500 \mathrm{~K}$. The location of the feature appears at different altitudes, varying between $80-110 \mathrm{~km}$. Out of the four different cases that we considered for comparison (four cases with MSPs and four cases without MSPs, so eight all together), the feature appears in four out of eight plots, one with MSPs and three without MSPs. 

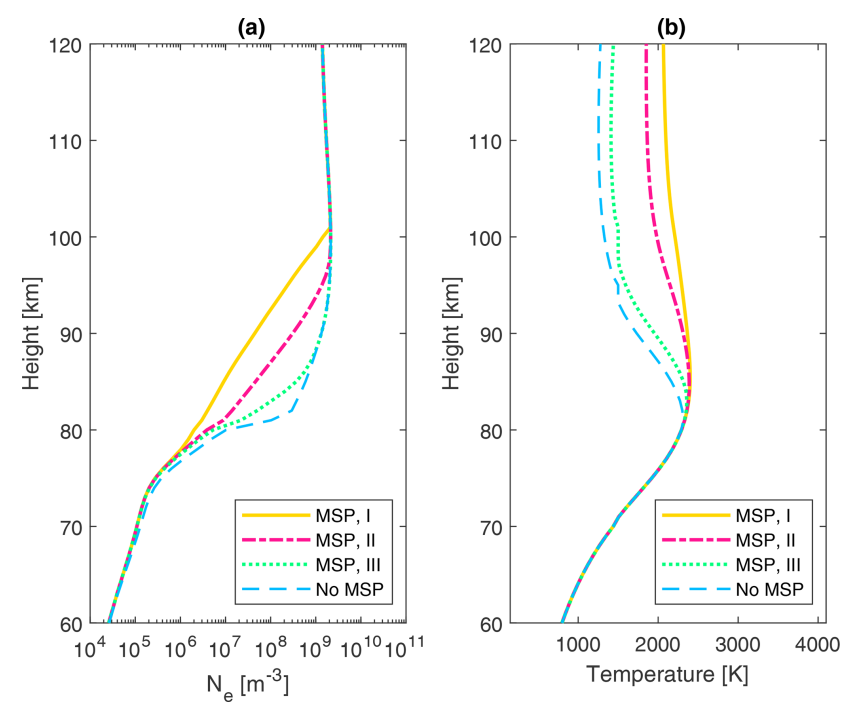

Figure 8. Result for different electron attachment efficiencies. Panel (a) shows electron density and panel (b) shows heated electron temperature. The legend describes the different size-dependent probabilities for electron attachment to MSP: "MSP, I" - the probability is 1 for all MSP sizes. "MSP, II" - the probability is zero for MSP sizes below $0.25 \mathrm{~nm}$; between 0.25 to $1.5 \mathrm{~nm}$ the probability increases linearly, and for sizes larger than $1.5 \mathrm{~nm}$ the probability is 1. "MSP, III" - the probability is zero for MSP size below $1.5 \mathrm{~nm}$ and 1 for sizes larger than $1.5 \mathrm{~nm}$. See Table 2 for more details on the different electron attachment efficiencies. We also show the model run without MSPs.

In Fig. 7 we show results for MSP winter distribution (night ionospheric conditions) and MSP summer distribution (day ionospheric conditions). Figure 7a shows electron density, while Fig. 7b shows heated electron temperature. For model run with MSPs, a comparison of electron densities in Figs. 7a and 4 show a slightly higher electron depletion below $80 \mathrm{~km}$ in the winter case compared to the autumn case. However, above $80 \mathrm{~km}$, the electron depletion is higher for the autumn case. For the winter case, the reduction in electron density extends to around $90 \mathrm{~km}$, while it extends to around $100 \mathrm{~km}$ for the autumn case. In Fig. 5, the heated electron temperature for the autumn case is higher above $80 \mathrm{~km}$ compared to the winter case in Fig. 7b; the difference is less than $280 \mathrm{~K}$. Our results in Fig. 7 for the summer case are quite similar to the autumn case. This applies to the behaviour of both the electron density and the heated electron temperature. The difference between the heated electron temperature for the summer case and the autumn case is less than $8 \mathrm{~K}$.

Figure 8 shows model results for different cases of electron attachment efficiencies of MSPs, where Fig. 8a shows electron density and Fig. $8 \mathrm{~b}$ shows heated electron temperature. In this study, we concentrate on three different scenarios for size-dependent probabilities of electron attachment to MSPs: "MSP, I" - the probability is 1 for all MSP sizes. "MSP, II"
- the probability is zero for MSP sizes below $0.25 \mathrm{~nm}$; between 0.25 to $1.5 \mathrm{~nm}$ the probability increases linearly, and for sizes larger than $1.5 \mathrm{~nm}$ the probability is 1. "MSP, III" the probability is zero for MSP size below $1.5 \mathrm{~nm}$ and 1 for sizes larger than $1.5 \mathrm{~nm}$. See also Table 2 for more details. We see in Fig. 8a that the magnitude of the reduced electron density depends on the electron attachment efficiency. In the case MSP, I, the electron density is severely reduced, because more MSPs are available to be charged. If there is no charging for sizes below $1.5 \mathrm{~nm}$, the electron density is quite similar to the electron density when no MSPs are present. This applies to the electron temperature in Fig. 8b as well. For the case where the probability is 1 for all sizes (MSP, I), the heated electron temperature remains almost constant from 90-120 km. The temperature difference between "MSP, I" and "MSP, III" goes up to $750 \mathrm{~K}$.

\subsection{Day conditions}

This section presents results for electron temperature modelled during artificial heating with and without the presence of MSPs for day conditions. Figure 9a shows electron density with and without MSPs. As for night conditions the electron density comes from the ionospheric model. We see that the electron bite-outs are much smaller in Fig. 9 compared to the results for night conditions in Fig. 4. Figure 9b shows the heated electron temperature for cases $1-4$. We see that the heated electron temperature is the same with and without MSPs. We find that the absolute difference between the electron temperature modelled with and without MSPs is less than $25 \mathrm{~K}$ for all cases $1-4$. Compared to night conditions, the day conditions electron temperature is lower. For cases 13 during day conditions, the electron temperature is below $2000 \mathrm{~K}$ for all altitudes. At around $90 \mathrm{~km}$, the electron temperature is back to the neutral temperature for all cases 1-4.

\section{Discussion}

Both Kero et al. (2007) and Senior et al. (2010) found that current models most likely overestimate artificial heating in the D-region compared to observations. Why the models overestimate artificial heating in the D-region remains an open question. Kero et al. (2007) studied how artificial heating influences cosmic radio noise absorption. Their study showed that the observed enhancement of cosmic radio noise absorption during heating is lower than predicted theoretically. Senior et al. (2010) used a cross-modulation technique with the EISCAT radar. They found that the model overestimates the diagnostic wave absorption. An explanation for the discrepancy between models and observations suggested by Senior et al. (2011) is that the modelled heater ERP is lower than predicted, because the assumption of a perfect reflecting ground around the antenna might not be applicable. Senior 

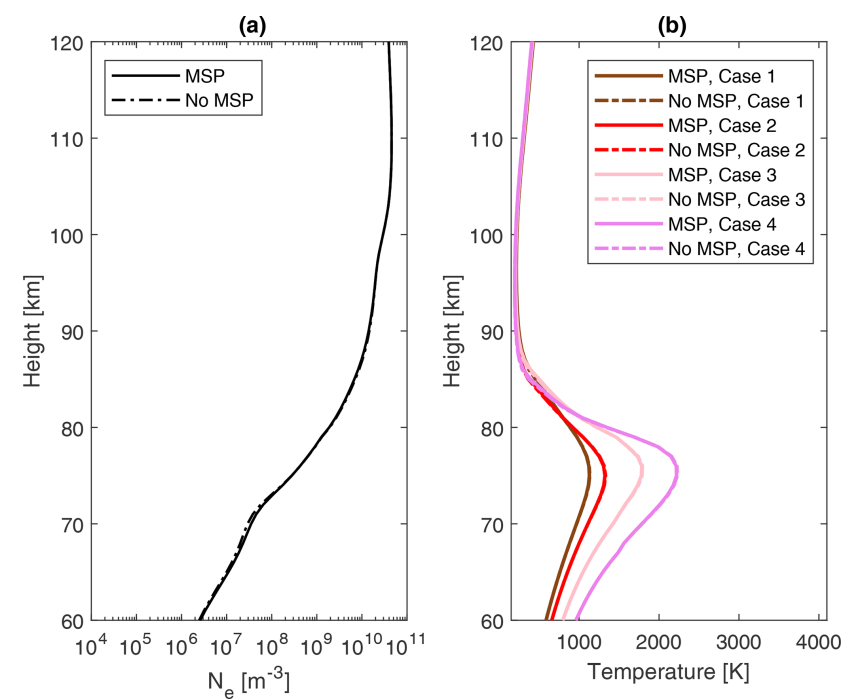

Figure 9. Results for day conditions. Panel (a) shows the electron density, which comes from the ionospheric model. Panel (b) shows the modelled electron temperature during heating as a function of height. The legend shows the model runs with and without the MSPs, as well as model run for the different cases 1-4.

et al. (2011) found that the overestimation is reduced when modelling the ERP with more realistic ground assumptions.

In the study by Senior et al. (2010), the authors note that electron bite-outs located at PMSE layer altitudes might influence the model, but the influence is probably small, because the bite-outs are located too high in altitude. They investigate the influence of the electron bite-outs by scaling the whole electron density profile with a factor of 2 or 0.5 . However, they do not include the height variation of the electron density profile when electron bite-outs are present. We find that electron bite-outs are only present at certain altitudes. The magnitude of the electron bite-outs varies within these altitudes; for instance, the electron bite-out is significantly larger between $80-100 \mathrm{~km}$ compared to between $70-80 \mathrm{~km}$. In our study, we have modelled the electron temperature during heating and included the height variation of the electron bite-outs. We have included the height variation of electron bite-outs by using the ionospheric model with MSPs, which presents a simplified model of the D-region by including height and size-dependent MSP distribution in a reaction scheme with electrons, ions, and neutral and charged MSPs. This enables us to have a more realistic representation of the height variation of the electron bite-outs. In a future study we will make a detailed comparison of our results to observations of the electron temperature during heating. This detailed comparison can investigate if the presence of MSPs explains the discrepancy between model and observations.

Figure 5 for night conditions shows that the electron temperature is higher and decreases more slowly when MSPs are present. An explanation for why the heated electron temperature decreases more slowly is that, with electron bite-outs at

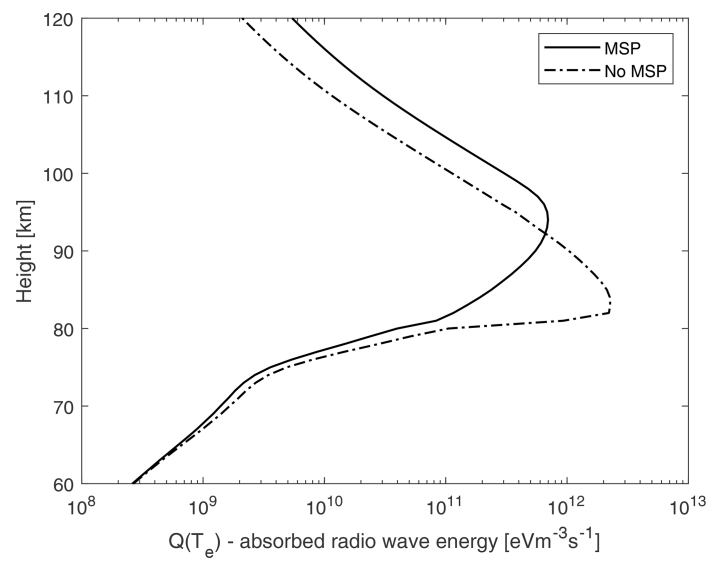

Figure 10. Absorbed radio wave energy $Q(=L)$ as a function of height for night conditions and case $2(5.5 \mathrm{MHz}$ and ERP of $600 \mathrm{MW}$ ). The legend shows the model runs with and without the MSPs. We show this figure to illustrate how the absorbed power varies with and without MSPs.

certain altitudes, the heating above these heights will be increased since less of the wave energy is absorbed within the electron bite-outs. The absorption of wave energy depends on electron density, and the absorption decreases with decreasing electron density. We see this effect in Fig. 10, which shows absorbed radio wave energy as a function of height. Here, less wave energy is absorbed when MSPs are present. More wave energy is absorbed at higher altitudes, slightly above where the electron bite-outs are largest in magnitude. The cooling rates also depend on electron density and decrease at higher altitudes due to a lower electron-neutral collision frequency since the neutral density is lower. The electron cooling-heating equality is reached at higher electron temperatures as more wave energy remains in the case with MSPs compared to the case without MSPs. An electron biteout at lower altitudes can lead to an increased electron temperature at higher altitudes above.

Our results in Fig. 8 for the different electron attachment efficiencies indicate that the heated electron temperature height profile is very dependent on the amount of chargeable MSPs. Increasing the amount of chargeable MSPs leads to a nearly vanishing electron density at altitudes between 80 and $100 \mathrm{~km}$. This aspect of MSPs is not very well known and could be investigated further. Note that the electron density profile in the case "MSP, I" might be unrealistically low since it is around 1 order of magnitude below the electron density measured during the ECOMA-7 rocket flight (between $80-95 \mathrm{~km}$ ), which is the lowest electron density ever measured at auroral latitudes (Friedrich et al., 2012). Given that the case "MSP, I" is indeed very unlikely indicates that there are either not that many small MSPs (sizes below $0.25 \mathrm{~nm}$ ) or that the smaller MSPs are not charged. The modelling with different electron attachment efficiencies (different charging) and with different MSP number density 
profiles indicates that the night-time D-region electron temperature varies with the number of chargeable MSPs, which again varies with the MSP number density and the charging efficiency.

The results of our study show that the frequency of the transmitted radio wave only plays a minor role. Lower frequency only slightly shifts the start of the heated ionosphere to a higher altitude. We also see that the increased electron temperature due to the presence of MSPs extends up to $120 \mathrm{~km}$ in the E-region. Our model for the heated electron temperature might not be applicable for the E-region; however, this is beyond the scope of this paper. The results from this study agree with Kassa et al. (2005), where an electron bite-out inserted as a linearly decreasing "toy model" between $84-86 \mathrm{~km}$ during PMSE conditions resulted in an increased modelled electron temperature within and above the electron bite-out.

Figure $9 \mathrm{~b}$ shows that electron temperature for day conditions is the same with and without MSPs. This indicates that, for day conditions, MSPs are less important for the heated electron temperature. A higher ionization level and thus a much higher electron density means that loss of electrons, like electron attachment to MSPs, is less important. Generally, the electron temperature is lower for day conditions. This is because the electron density is higher during the day, also at lower heights. The electron density in Fig. 9a is $2.5 \times 10^{6} \mathrm{~m}^{-3}$ at $60 \mathrm{~km}$ for day conditions, while for night conditions the electron density in Fig. 4 is $2.6 \times 10^{4} \mathrm{~m}^{-3}$ at $60 \mathrm{~km}$. With a higher electron density as during day conditions, the radio wave energy is absorbed already at lower heights.

In Fig. 5 there is a feature in some of the plots of the heated night conditions electron temperature. This feature can resemble a small second maximum, or it might just be an artefact. It appeared when we included the temperature dependence of the cooling rates for vibrational excitation of molecular nitrogen; the values from Pavlov (1998a) that we use are different for the temperatures $300 \leq T_{\mathrm{e}} \leq 1500 \mathrm{~K}$ and for those $T_{\mathrm{e}}>1500 \mathrm{~K}$. The feature that we note is at electron temperature around $1500 \mathrm{~K}$. The feature disappears if we apply the same values for vibrational excitation of molecular nitrogen over the entire range of temperatures and disregard the difference for the $T_{\mathrm{e}} \leq 1500 \mathrm{~K}$ case. Kero et al. (2008) found a second maximum in the EISCAT incoherent scatter observations for the heated electron temperature in the D-region, which they could not explain. The feature in Fig. 5 might be a second maximum, or it might be an artefact caused by problems in the numerical modelling when switching between values for $T_{\mathrm{e}} \leq 1500 \mathrm{~K}$ and $T_{\mathrm{e}}>1500 \mathrm{~K}$. Whether the feature is an artefact or not is unknown at the present and can be investigated further. The feature is not seen in the day conditions electron temperature in Fig. $9 \mathrm{~b}$.

\section{Conclusions}

The presented model calculations show that the presence of MSPs can influence the electron temperature during artificial heating. The influence of the MSPs varies with ionospheric conditions. For night conditions, the results show a higher heated electron temperature above altitudes of $80 \mathrm{~km}$ when MSPs are present. We found differences of up to $1000 \mathrm{~K}$ in temperature for calculations with and without MSPs. Below $80 \mathrm{~km}$ of altitude for night conditions the difference in temperature is small for model calculations with and without MSPs. For day conditions, the difference between the heated electron temperature with MSPs and without MSPs is less than $25 \mathrm{~K}$. This study indicates that MSPs can influence both the magnitude and shape of the heated electron temperature above $80 \mathrm{~km}$; however, this depends on ionospheric conditions.

Furthermore, we model with different MSP number density profiles for autumn, summer and winter. The results show $280 \mathrm{~K}$ hotter night-time electron temperature for autumn compared to winter, while for the daytime electron temperature the autumn case is $8 \mathrm{~K}$ cooler than the summer case. However, this varies with altitude. Finally, our results show that the electron attachment efficiency influences the heated electron temperature by impacting the amount of chargeable MSPs. In future studies, we will model the D-region electron temperature during artificial heating with a non-Maxwellian electron velocity distribution, possibly combining it with our study about artificial heating and MSPs.

\section{Appendix A: MSP number density profiles}

Figure A1 shows the different MSP number density profiles: Fig. A1a shows the MSP autumn case (Megner et al., 2006) for 8 September, Fig. A1b shows the MSP winter case (Megner et al., 2008) for 1 January and Fig. A1c shows the MSP summer case (Megner et al., 2008) for 20 July. The MSP number density profile for autumn and winter is quite similar. However, the difference between the winter and summer cases is quite significant, particularly for the larger sizes above $5 \mathrm{~nm}$, which is more abundant for the summer case and extends to a higher altitude as well.

\section{Appendix B: Electron cooling rates}

The electrons lose energy through collisions with the neutral gases. The dominant cooling processes related to $\left[\mathrm{N}_{2}\right]$ and $\left[\mathrm{O}_{2}\right]$ are the energy transfer via vibrational and rotational excitation (see Rietveld et al., 1986; Gustavsson et al., 2010). Even though the concentration of atomic oxygen is very small between $60-100 \mathrm{~km}$ (as discussed by Senior et al., 2010), we will include electron cooling rates for atomic oxygen [O] through the impact excitation of fine structure levels of its ground state (see Pavlov and Berringston, 1999, and 

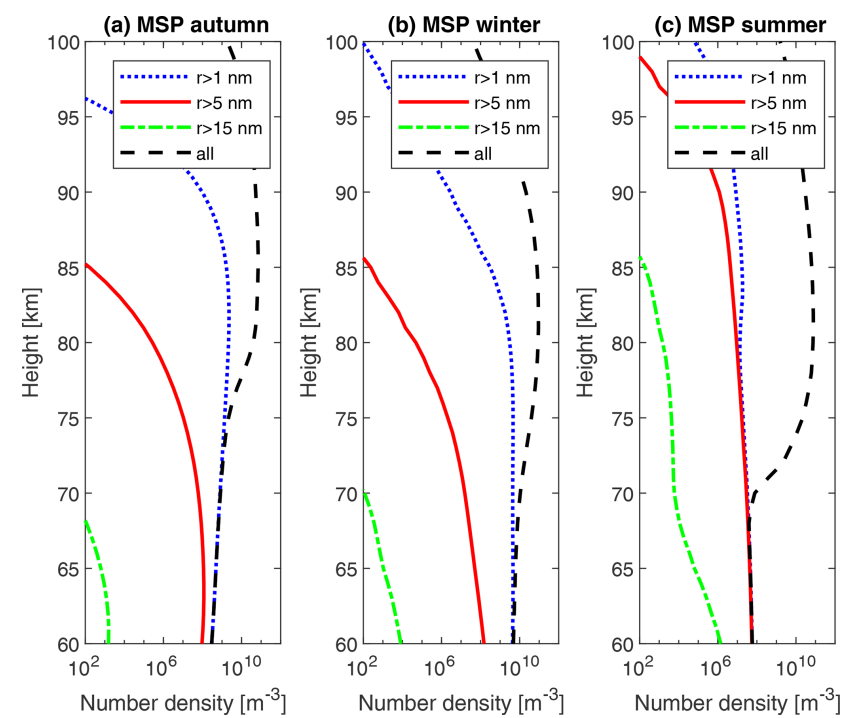

$$
S_{10}=8.249 \times 10^{-16} \cdot T_{\mathrm{e}}^{0.6} \exp \left(-227.7 \cdot T_{\mathrm{n}}^{-1}\right) .
$$

The $S_{i j}$ denotes the transitions between the three fine structure levels of the atomic oxygen ground state.

For vibrational excitation of molecular nitrogen, we use Eq. (11) from Pavlov (1998a) for a Boltzmann distribution:

$$
\begin{aligned}
L_{\mathrm{vib}}\left(\mathrm{N}_{2}\right) & =N_{\mathrm{e}}\left[\mathrm{N}_{2}\right]\left\{1-\exp \left(-E_{1} / T_{\mathrm{vib}}\right)\right\} \\
& \times \sum_{v=1}^{10} Q_{0 \mathrm{v}}\left\{1-\exp \left[v E_{1}\left(T_{\mathrm{e}}^{-1}-T_{\mathrm{vib}}^{-1}\right)\right]\right\} \\
& +N_{\mathrm{e}}\left[\mathrm{N}_{2}\right]\left\{1-\exp \left(-E_{1} / T_{\mathrm{vib}}\right)\right\}\left(\exp \left(-E_{1} / T_{\mathrm{vib}}\right)\right) \\
& \times \sum_{v=2}^{9} Q_{1 \mathrm{v}}\left\{1-\exp \left[(v-1) E_{1}\left(T_{\mathrm{e}}^{-1}-T_{\mathrm{vib}}^{-1}\right)\right]\right\}
\end{aligned}
$$

where $E_{1}=3353 \mathrm{~K}$ is the energy of the first vibrational level of $\left[\mathrm{N}_{2}\right]$ and we assume that the vibrational temperature is equal to the neutral temperature. The units of $L_{\mathrm{vib}}\left(\mathrm{N}_{2}\right)$ are $\mathrm{eV} \mathrm{cm}^{-3} \mathrm{~s}^{-1}$. Here, $Q_{0 \mathrm{v}}$ describes excitation transitions from ground states, and $Q_{1 \mathrm{v}}$ describes excitation transitions from the first vibrational state. For $Q_{0 \mathrm{v}}$ and $Q_{1 \mathrm{v}}$, we implement Eqs. (19) and (20) from Pavlov (1998a), respectively:

$\log Q_{0 \mathrm{v}}=A_{0 \mathrm{v}}+B_{0 \mathrm{v}} T_{\mathrm{e}}+C_{0 \mathrm{v}} T e^{2}+D_{0 \mathrm{v}} T e^{3}+F_{0 \mathrm{v}} T e^{4}-16$, is between $60-120 \mathrm{~km}$, and the concentration of atomic oxygen increases above $100 \mathrm{~km}$. At $120 \mathrm{~km}$, the concentration of atomic oxygen is in the same order of magnitude as the concentration of molecular oxygen. We here repeat the cooling rates that are used. The sum of the electron cooling rates are the energy loss function, given as

$$
\begin{aligned}
L\left(T_{\mathrm{e}}\right) & =L_{\mathrm{fs}}(\mathrm{O})+L_{\mathrm{vib}}\left(\mathrm{N}_{2}\right)+L_{\mathrm{rot}}\left(\mathrm{N}_{2}\right)+L_{\mathrm{vib}}\left(\mathrm{O}_{2}\right) \\
& +L_{\mathrm{rot}}\left(\mathrm{O}_{2}\right)+L_{\mathrm{el}}\left(\mathrm{N}_{2}\right)+L_{\mathrm{el}}\left(\mathrm{O}_{2}\right)+L_{\mathrm{el}}(\mathrm{O}) .
\end{aligned}
$$

The units of $L\left(T_{\mathrm{e}}\right)$ are in $\mathrm{J} \mathrm{m}^{-3} \mathrm{~s}^{-1}$.

To describe the excitation of fine structure levels of atomic oxygen, we use Eq. (15) from Pavlov and Berringston (1999):

$$
\begin{aligned}
L_{\mathrm{fs}}(\mathrm{O}) & =N_{\mathrm{e}}[\mathrm{O}] D^{-1}\left(S_{10}\left\{1-\exp \left[98.9\left(T_{\mathrm{e}}^{-1}-T_{\mathrm{n}}^{-1}\right)\right]\right\}\right. \\
& +S_{20}\left\{1-\exp \left[326.6\left(T_{\mathrm{e}}^{-1}-T_{\mathrm{n}}^{-1}\right)\right]\right\} \\
& \left.+S_{21}\left\{1-\exp \left[227.7\left(T_{\mathrm{e}}^{-1}-T_{\mathrm{n}}^{-1}\right)\right]\right\}\right) .
\end{aligned}
$$

The units of Eq. (B2) are $\mathrm{eV} \mathrm{cm}^{-3} \mathrm{~s}^{-1}$, and $T_{\mathrm{n}}$ is the neutral temperature. Both $T_{\mathrm{e}}$ and $T_{\mathrm{n}}$ are in kelvin (K). The equation is based on assuming that the electron velocity distribution is Maxwellian. The terms $D, S_{21}, S_{20}$ and $S_{10}$ are

$$
\begin{aligned}
& D=5+\exp \left(-326.6 \cdot T_{\mathrm{n}}^{-1}\right)+3 \exp \left(-227.7 \cdot T_{\mathrm{n}}^{-1}\right), \\
& S_{21}=1.863 \times 10^{-11}, \\
& S_{20}=1.191 \times 10^{-11},
\end{aligned}
$$

$\log Q_{1 \mathrm{v}}=A_{1 \mathrm{v}}+B_{1 \mathrm{v}} T_{\mathrm{e}}+C_{1 \mathrm{v}} T e^{2}+D_{1 \mathrm{v}} T e^{3}+F_{1 \mathrm{v}} T e^{4}-16$,

where the coefficients $A_{0 \mathrm{v}}, B_{0 \mathrm{v}}, C_{0 \mathrm{v}}, D_{0 \mathrm{v}}$ and $F_{0 \mathrm{v}}$ to compute $Q_{0 \mathrm{v}}$ and $A_{1 \mathrm{v}}, B_{1 \mathrm{v}}, C_{1 \mathrm{v}}, D_{1 \mathrm{v}}$ and $F_{1 \mathrm{v}}$ to compute $Q_{1 \mathrm{v}}$ comes from tables in Pavlov (1998a). For $Q_{0 \mathrm{v}}$ from Table 1 in Pavlov (1998a) for $300 \leq T_{\mathrm{e}} \leq 1500 \mathrm{~K}$ and from Table 2 in Pavlov (1998a) for $T_{\mathrm{e}}>1500 \mathrm{~K}$. For $Q_{1 \mathrm{v}}$ from Table 3 in Pavlov (1998a) for $1500 \leq T_{\mathrm{e}} \leq 6000 \mathrm{~K}$. However, there is no table for $Q_{1 \mathrm{v}}$ for $T_{\mathrm{e}}<1500 \mathrm{~K}$ in Pavlov (1998a). Both $Q_{0 \mathrm{v}}$ and $Q_{1 \mathrm{v}}$ have units $\mathrm{eV} \mathrm{cm}^{3} \mathrm{~s}^{-1}$. Rotational excitation of molecular nitrogen come from Eq. (A2) in Pavlov (1998a):

$C=3.51 \times 10^{-14}$

$L_{\mathrm{rot}}\left(\mathrm{N}_{2}\right)=C\left[\mathrm{~N}_{2}\right] N_{\mathrm{e}}\left(T_{\mathrm{e}}-T_{\mathrm{n}}\right) T e^{-0.5}$.

The units of $C$ and $L_{\text {rot }}\left(\mathrm{N}_{2}\right)$ are $\mathrm{eV} \mathrm{cm}^{3} \mathrm{~s}^{-1} \mathrm{~K}^{-0.5}$ and $\mathrm{eV} \mathrm{cm}^{-3} \mathrm{~s}^{-1}$, respectively.

For vibrational excitation of molecular oxygen, we use Eq. (8) from Pavlov (1998b), which assumes a Boltzmann distribution:

$L_{\text {vib }}\left(\mathrm{O}_{2}\right)=N_{\mathrm{e}}\left[\mathrm{O}_{2}\right] \sum_{v=2}^{7} Q_{0 \mathrm{v}}^{*}\left\{1-\exp \left[v E_{1}\left(T_{\mathrm{e}}^{-1}-T_{\mathrm{vib}}^{-1}\right)\right]\right\}$

in units $\mathrm{eV} \mathrm{cm}^{-3} \mathrm{~s}^{-1}$ and where $E_{1}=2239 \mathrm{~K}$ is the energy of the first vibrational level of $\left[\mathrm{O}_{2}\right]$, and we set $T_{\mathrm{vib}}=T_{\mathrm{n}}$. Here $Q_{0 \mathrm{v}}$ describes excitation transitions from ground states. $Q_{0 \mathrm{v}}$ comes from Eq. (11) in Pavlov (1998b):

$Q_{0 \mathrm{v}}^{*}=A_{\mathrm{v}} \exp \left\{\left(1-B_{\mathrm{v}} T e^{-1}\right)\left(C_{\mathrm{v}}+D_{\mathrm{v}} \sin \left[F_{\mathrm{v}}\left(T_{\mathrm{e}}-G_{\mathrm{v}}\right)\right]\right)\right\}$, 


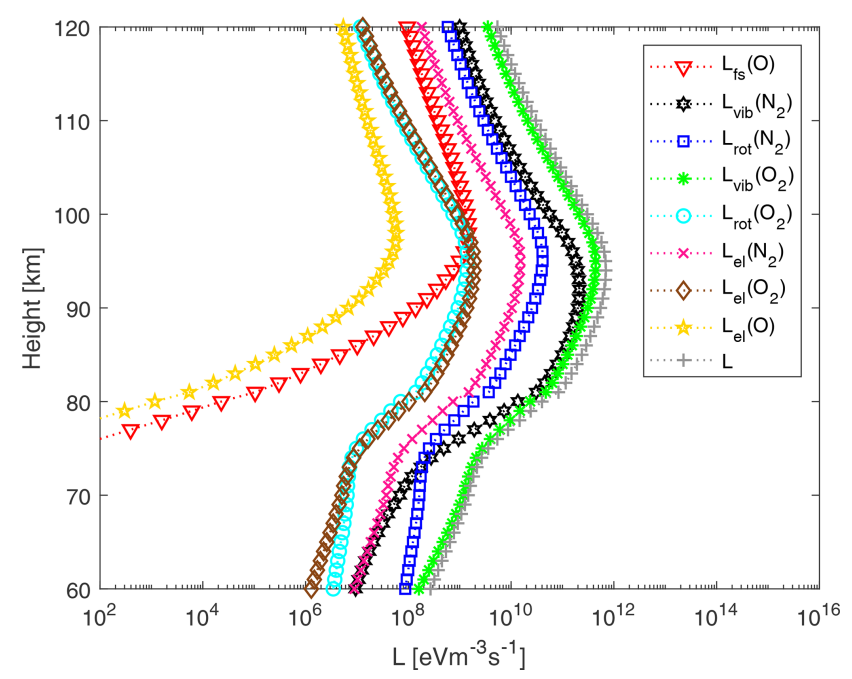

Figure B1. Night conditions electron cooling rates with MSP as a function of height for a heated electron temperature. The frequency is $5.5 \mathrm{MHz}$ and ERP is $600 \mathrm{MW}$. The legend shows the different cooling rates as described in this section.

where the coefficients $A_{\mathrm{v}}, B_{\mathrm{v}}, C_{\mathrm{v}}, D_{\mathrm{v}}, F_{\mathrm{v}}, G_{\mathrm{v}}$ as a function of vibrational level come from Table 1 of Pavlov (1998b). For rotational excitation of $\left[\mathrm{O}_{2}\right]$ we use Eq. (16), also from Pavlov (1998b):

$C_{\mathrm{O}_{2}}=5.2 \times 10^{-15}$,

$L_{\text {rot }}\left(\mathrm{O}_{2}\right)=C_{\mathrm{O}_{2}}\left[\mathrm{O}_{2}\right] N_{\mathrm{e}}\left(T_{\mathrm{e}}-T_{\mathrm{n}}\right) T_{\mathrm{e}}^{-0.5}$,

where $C_{\mathrm{O}_{2}}$ has units of $\mathrm{eV} \mathrm{cm}^{3} \mathrm{~s}^{-1} \mathrm{~K}^{-0.5}$, and $L_{\mathrm{rot}}\left(\mathrm{O}_{2}\right)$ has units $\mathrm{eV} \mathrm{cm}^{-3} \mathrm{~s}^{-1}$. For elastic collisions between electrons and neutrals (molecular nitrogen, molecular oxygen and atomic oxygen, respectively) we implement Eq. $(43 \mathrm{a}-\mathrm{c})$ from Schunk and Nagy (1978):

$$
\begin{aligned}
L_{\mathrm{el}}\left(\mathrm{N}_{2}\right)= & N_{\mathrm{e}}\left[\mathrm{N}_{2}\right] 1.77 \times 10^{-19} T_{\mathrm{e}}\left(T_{\mathrm{e}}-T_{\mathrm{n}}\right) \\
& \left(1-1.21 \times 10^{-4} T_{\mathrm{e}}\right) \\
L_{\mathrm{el}}\left(\mathrm{O}_{2}\right)= & N_{\mathrm{e}}\left[\mathrm{O}_{2}\right] 1.21 \times 10^{-18} \sqrt{T_{\mathrm{e}}}\left(T_{\mathrm{e}}-T_{\mathrm{n}}\right) \\
& \left(1+3.6 \times 10^{-2} \sqrt{T_{\mathrm{e}}}\right) \\
L_{\mathrm{el}}(\mathrm{O})= & N_{\mathrm{e}}[\mathrm{O}] 7.9 \times 10^{-19} \sqrt{T_{\mathrm{e}}}\left(T_{\mathrm{e}}-T_{\mathrm{n}}\right) \\
& \left(1+5.7 \times 10^{-4} T_{\mathrm{e}}\right)
\end{aligned}
$$

In Figs. B1 and B2 we present height profiles for electron cooling rates for night conditions. We show electron cooling rates for a heated electron temperature. Figure B1 shows cooling rates where MSPs are present, while Fig. B2 shows cooling rates where MSPs are not present. The frequency is $5.5 \mathrm{MHz}$ and ERP is $600 \mathrm{MW}$.

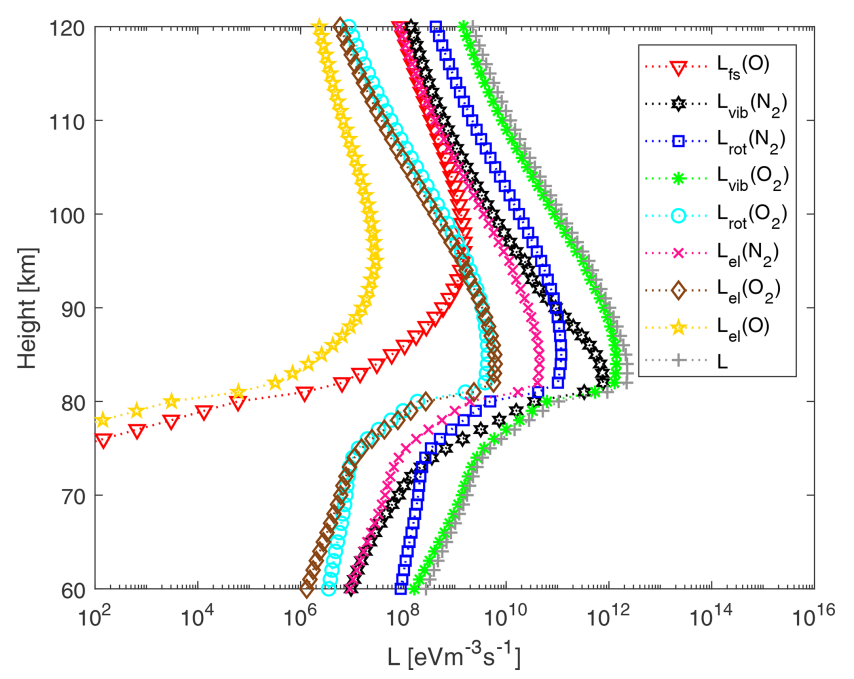

Figure B2. Night conditions electron cooling rates without MSP as a function of height for a heated electron temperature. The frequency is $5.5 \mathrm{MHz}$ and ERP is $600 \mathrm{MW}$. The legend shows the different cooling rates as described in this section.

Code and data availability. A function that computes the electron temperature and radio wave intensity during artificial heating, including the electron cooling rates, is available at Myrvang (2021) (https://doi.org/10.18710/D4REDW). Data sets, which contain electron density altitude profiles from the background ionospheric model (Baumann et al., 2013) can be found at Baumann and Myrvang (2021) (https://doi.org/10.5281/zenodo.5668082).

Author contributions. MM made the artificial heating program and prepared the initial manuscript. CB developed the ionospheric model. IM suggested the topic and supervised the project. All authors contributed to the preparation of the manuscript.

Competing interests. At least one of the (co-)authors is a member of the editorial board of Annales Geophysicae. The peer-review process was guided by an independent editor, and the authors also have no other competing interests to declare.

Disclaimer. Publisher's note: Copernicus Publications remains neutral with regard to jurisdictional claims in published maps and institutional affiliations.

Acknowledgements. We would like to thank Ove Havnes for providing us with a program from Meseret Kassa. We have compared our results to this program. In addition, we would like to thank Antti Kero for the suggestion to look at how the presence of MSP can influence artificial heating. We would like to thank Björn Gustavsson for helping us with the theory of artificial heating. This work was supported by the Research Council of Norway through grant no. NFR 275503, "The Mesospheric Dust in Small Size Limit”. The 
publication charges for this article have been funded by a grant from the publication fund of UiT The Arctic University of Norway.

Financial support. This research has been supported by the Norges Forskningsråd (grant no. 275503).

Review statement. This paper was edited by Dalia Buresova and reviewed by two anonymous referees.

\section{References}

Baumann, C. and Myrvang, M.: Lower ionospheric electron densities based on a simple ionospheric model that uses MSP as charge carrier, Zenodo [data set], https://doi.org/10.5281/zenodo.5668082, 2021.

Baumann, C., Rapp, M., Kero, A., and Enell, C.-F.: Meteor smoke influence on the D-region charge balance - review of recent in situ measurements and one-dimensional model results, Ann. Geophys., 31, 2049-2062, https://doi.org/10.5194/angeo31-2049-2013, 2013.

Baumann, C., Rapp, M., Anttila, M., Kero, A., and Verronen, P.: Effects of meteoric smoke particles on the D-region ion chemistry, J. Geophys. Res.-Space, 120, 10823-10839, https://doi.org/10.1002/2015JA021927, 2015.

Belova, E. G., Pashin, A. B., and Lyatsky, W. B.: Passage of a powerful HF radio wave through the lower ionosphere as a function of initial electron density profiles, J. Atmos. Terr. Phys., 57, 265272, https://doi.org/10.1016/0021-9169(93)E0012-X, 1995.

Biebricher, A. and Havnes, O.: Non-equilibrium modelling of the PMSE overshoot effect revisited: A comprehensive study, J. Plasma Phys., 78, 303-319, https://doi.org/10.1017/S0022377812000141, 2012.

Brekke, A.: Physics of the upper polar atmosphere, 2nd Edn., Springer-Verlag, Berlin, Heidelberg, 2013.

Brent, R.: Algorithms for Minimization Without Derivatives, Prentice-Hall, Englewood Cliffs, New Jersey, 1973.

Chilson, P. B., Belova, E., Rietveld, M. T., Kirkwood, S., and Hoppe, U.-P.: First artificially induced modulation of PMSE using the EISCAT heating facility, Geophys. Res. Lett., 27, 38013804, https://doi.org/10.1029/2000GL011897, 2000.

Dalgarno, A., McElroy, M. B., and Walker, J. C. G.: The diurnal variation of ionospheric temperatures, Planet. Space Sci., 15, 331-345, https://doi.org/10.1016/0032-0633(67)90198-5, 1967.

Forsythe, G. E., Malcolm, M. A., and Mole, C. B.: Computer Methods for Mathematical Computations, 1st Edn., Prentice-Hall, Englewood Cliffs, New Jersey, 1977.

Friedrich, M., Rapp, M., Blix, T., Hoppe, U. P., Torkar, K., Robertsen, S., Dickson, S., and Lynch, K.: Electron loss and meteoric dust in the mesosphere, Ann. Geophys., 30, 1495-1501, https://doi.org/10.5194/angeo-30-1495-2012, 2012.

Gustavsson, B., Rietveld, M. T., Ivchenko, N. V., and Kosch, M. J.: Rise and fall of electron temperature: Ohmic heating of ionospheric electrons from underdense HF radio wave pumping, J. Geophys. Res., 115, A12332, https://doi.org/10.1029/2010JA015873, 2010.
Havnes, O., Hoz, C. L., , Biebricher, A., Kassa, M., Næsheim, L. I. and Zivkovic, T.: Investigation of the mesospheric PMSE conditions by use of the new overshoot effect, Phys. Scripta, T107, 7078, https://doi.org/10.1238/Physica.Topical.107a00070, 2004.

Hedin, A. E.: Extension of the MSIS thermosphere model into the middle and lower atmosphere, J. Geophys. Res., 96, 1159-1172, 1991.

Hunten, D. M., Turco, R. P., and Toon, O. B.: Smoke and Dust Particles of Meteoric Origin in the Mesosphere and Stratosphere, J. Atmos. Sci., 37, 1342-1357, 1980.

Kassa, M., Havnes, O., and Belova, E.: The effect of electron bite-outs on artificial electron heating and the PMSE overshoot, Ann. Geophys., 23, 3633-3643, https://doi.org/10.5194/angeo23-3633-2005, 2005.

Kero, A., Bösinger, T., Pollari, P., Turunen, E., and Rietveld, M.: First EISCAT measurement of electron-gas temperature in the artificially heated D-region ionosphere, Ann. Geophys., 18, 12101215, https://doi.org/10.1007/s00585-000-1210-8, 2000.

Kero, A., Enell, C. F., Ulich, T., Turunen, E., Rietveld, M. T., and Honary, F. H.: Statistical signature of active D-region HF heating in IRIS riometer data from 1994-2004, Ann. Geophys., 25, 407415, https://doi.org/10.5194/angeo-25-407-2007, 2007.

Kero, A., Vierinen, J., Enell, C. F., Virtanen, I., and Turunen, E.: New incoherent scatter diagnostic methods for the heated D-region ionosphere, Ann. Geophys., 26, 2273-2279, https://doi.org/10.5194/angeo-26-2273-2008, 2008.

Kosch, M., Bryers, J. C., Rietveld, M., Yeoman, T. K., and Ogawa, Y.: Aspect angle sensitivity of pump-induced optical emission at EISCAT, Earth Planets Space, 66, 159, https://doi.org/10.1186/s40623-014-0159-x, 2014.

Kosch, M. J., Rietveld, M. T., Hagfors, T., and Leyser, T. B.: Highlatitude HF-induced airglow displaced equatorwards of the pump beam, Geophys. Res. Lett., 27, 2817-2820, 2000.

Kosch, M. J., Ogawa, Y., Rietveld, M. T., Nozawa, S., and Fujii, R.: An analysis of pump-induced artificihttps://doi.org/al ionospheric ion upwelling at EISCAT, J. Geophys. Res.-Space, 115, A12317, 623-637, 10.1029/2010JA015854, 2010.

Megner, L. and Gumbel, J.: Charged meteoric particles as ice nuclei in the mesosphere: Part 2 A feasibility study, J. Atmos. Sol.-Terr. Phy., 71, 1236-1244, https://doi.org/10.1016/j.jastp.2009.05.002, 2009.

Megner, L., Rapp, M., and Gumbel, J.: Distribution of meteoric smoke-sensitivity to microphysical properties and atmospheric conditions, Atmos. Chem. Phys., 6, 4415-4426, https://doi.org/10.5194/acp-6-4415-2006, 2006.

Megner, L., Siskind, D. E., Rapp, M., and Gumbel, J.: Global and temporal distribution of meteoric smoke: A twodimensional simulation study, J. Geophys. Res., 113, D03202, https://doi.org/10.1029/2007JD009054, 2008.

Myrvang, M.: Modelling the influence of meteoric smoke particles on artificial heating in the D-region, DataverseNO [code], https://doi.org/10.18710/D4REDW, 2021.

Pavlov, A. V.: New electron energy transfer rates for vibrational excitation of $\mathrm{N}_{2}$, Ann. Geophys., 16, 176-182, 1998a.

Pavlov, A. V.: New electron energy transfer and cooling rates for vibrational excitation of $\mathrm{O}_{2}$, Ann. Geophys., 16, 1007-1013, 1998 b. 
Pavlov, A. V. and Berringston, K. A.: Cooling rates of thermal electrons by electron impact excitation of fine structure levels of atomic oxygen, Ann. Geophys., 17, 919-924, 1999.

Picone, J., Hedin, A., Drob, D., and Aikin, A.: NRLMSISE00 empirical model of the atmosphere: Statistical comparisons and scientific issues, J. Geophys. Res., 107, 1468, https://doi.org/10.1029/2002JA009430, 2002.

Plane, J. M. C.: A time-resolved model of the mesospheric Na layer: constraints on the meteor input function, Atmos. Chem. Phys., 4, 627-638, https://doi.org/10.5194/acp-4-627-2004, 2004.

Plane, J. M. C.: Cosmic dust in the Earth's atmosphere, Chem. Soc. Rev., 41, 6507-6518, https://doi.org/10.1039/c2cs35132c, 2012.

Rietveld, M. T., Kopka, H., and Stubbe, P.: D-region characteristics deduced from pulsed ionsospheric heating during auroral electrojet conditions, J. Atmos. Terr. Phys., 48, 311-326, https://doi.org/10.1016/0021-9169(86)90001-2, 1986.

Rietveld, M. T., Kohl, H., Kopka, H., and Stubbe, P.: Introduction to ionospheric heating at Troms $\varnothing$. Experimental overview, J. Atmos. Terr. Phys., 55, 577-599, https://doi.org/10.1016/00219169(93)90007-L, 1993.

Rietveld, M. T., Senior, A., Markkanen, J., and Westman, A.: New capabilities of the upgraded EISCAT high-power HF facility, Radio Sci., 51, 1533-1546, https://doi.org/10.1002/2016RS006093, 2016.
Robinson, T.: The heating of the high latitude ionossphere by high power radio waves, Phys. Rep., 179, 79-209, 1989.

Schunk, R. W. and Nagy, A. F.: Electron temperature in the F-region of the ionosphere: Theory and observations, Rev. Geophys., 16, 355-399, 1978.

Senior, A., Rietveld, M. T., Kosch, M. J., and Singer, W.: Diagnosing radio plasma heating in the polar summer mesosphere using cross modulation: Theory and observations, J. Geophys. Res., 115, A09318, https://doi.org/10.1029/2010JA015379, 2010.

Senior, A., Rietveld, M. T., Honary, F., Singer, W., and Kosch, M. J.: Measurements and modeling of cosmic noise absorption changes due to radio heating of the D region ionosphere, J. Geophys. Res., 116, A04310, https://doi.org/10.1029/2010JA016189, 2011.

Turunen, E., Matveinen, H., Tolvanen, J., and Ranta, H.: STEP Handbook of Ionospheric Models, chap. D-region ion chemistry model, SCOSTEP Secretariat, Sodankylä Geophysical Observatory, Sodankylä, Finland, 1-25, 1996.

Verronen, P. T., Andersson, M. E., Marsh, D. R., Kovacs, T., and Plane, J. M. C.: WACCM-D - Whole Atmosphere Community Climate Model with D-region ion chemistry, J. Adv. Model. Earth Syst., 8, 954-975, https://doi.org/10.1002/2015MS000592, 2016. 